九州大学学術情報リポジトリ

Kyushu University Institutional Repository

右側起始てんかん発作は，左側起始と比較して，発 作時心拍数がより上昇し, 発作後の副交感神経活動 はより高い

進村，光規

ht tps://doi. org/10.15017/4059946

出版情報：Kyushu University，2019，博士（医学），課程博士 バージョン：

権利関係: (C) 2019 Elsevier Inc. All rights reserved. 


\title{
Higher postictal parasympathetic activity following greater ictal heart rate increase in right- than left-sided seizures
}

\author{
Mitsunori Shimmura a , Taira Uehara ${ }^{a}$, Katsuya Ogata ${ }^{\text {b }}$, Hiroshi Shigeto a, Tomoko Maeda ${ }^{\text {, }}$, Ayumi Sakata ${ }^{\text {, }}$ \\ Ryo Yamasaki ${ }^{\text {a }}$ Jun-ichi Kira ${ }^{\text {a,* }}$ \\ a Department of Neurology, Neurological Institute, Graduate School of Medical Sciences, Kyushu University, 3-1-1 Maidashi, Higashi-ku, Fukuoka 812-8582, Japan \\ ${ }^{\mathrm{b}}$ Department of Clinical Neurophysiology, Neurological Institute, Graduate School of Medical Sciences, Kyushu University, 3-1-1 Maidashi, Higashi-ku, Fukuoka 812-8582, Japan \\ ${ }^{\mathrm{c}}$ Division of Clinical Chemistry and Laboratory Medicine, Kyushu University Hospital, 3-1-1 Maidashi, Higashi-ku, Fukuoka 812-8582, Japan
}

\section{A R T I C L E I N F O}

\section{Article history:}

Received 7 January 2019

Revised 10 May 2019

Accepted 17 May 2019

Available online $\mathrm{xxxx}$

\section{Keywords:}

Focal epilepsy

Heart rate variability

Autonomic nervous system

Hemispheric laterality

\begin{abstract}
A B S T R A C T
Objectives: The objectives of this study were to determine how hemispheric laterality of seizure activity influences periictal heart rate variability (HRV) and investigate the ability of HRV parameters to discriminate rightand left-sided seizures.

Methods: Long-term video electroencephalogram-electrocardiogram recordings of 54 focal seizures in 25 patients with focal epilepsy were reviewed. Using linear mixed models, we examined the effect of seizure laterality on linear (standard deviation of R-R intervals [SDNN], root mean square of successive differences [RMSSD], low frequency $[\mathrm{LF}]$ and high frequency $[\mathrm{HF}]$ power of $\mathrm{HRV}$, and $\mathrm{LF} / \mathrm{HF}$ ) and nonlinear (standard deviation [SD]1, SD2, and SD2/SD1 derived from Poincaré plots) periictal HRV parameters, the magnitude of heart rate (HR) changes, and the onset time of increased HR. Receiver operating characteristics (ROC) were used to determine the ability of these parameters to discriminate between right- and left-sided seizures.

Results: Postictal SDNN, RMSSD, LF, HF, SD1, and SD2 were higher in right- than left-sided seizures. Root mean square of successive difference and HF were decreased after left- but not right-sided seizures. Standard deviation of R-R intervals, LF, and SD1 were increased after right- but not left-sided seizures. Increased ictal HR was earlier and larger in right- than left-sided seizures. Postictal HF showed the greatest area under the ROC curve (AUC) (0.87) for discriminating right- and left-sided seizures.

Conclusions: Our data suggest that postictal parasympathetic activity is higher, whereas ictal HR increase is greater, in right- than left-sided seizures. Involvement of the right hemisphere may be associated with postictal autonomic instability. Postictal HRV parameters may provide useful information on hemispheric laterality of seizure activity.
\end{abstract}

(c) 2019 Elsevier Inc. All rights reserved.

\section{Introduction}

Autonomic cardiovascular control is thought to be asymmetrically represented in the brain, whereby the right hemisphere predominantly modulates sympathetic tone and the left hemisphere modulates parasympathetic tone [1-3]. Heart rate variability (HRV) is the variation in duration between consecutive heartbeats and reflects the sympathetic and parasympathetic control of heart rate (HR) [4]. Although interictal HRV changes in people with epilepsy have been described in some detail [5], relatively little is known about preictal and postictal HRV changes. Particularly, the effects of individual hemispheres remain unclear. Here, we hypothesized that seizure-induced HRV changes depend on the side of seizure focus and may be useful in lateralizing seizures. Furthermore, postictal rather than ictal autonomic changes are thought

\footnotetext{
* Corresponding author.

E-mail address: kira@neuro.med.kyushu-u.ac.jp (J. Kira).
}

to contribute to sudden unexpected death in epilepsy (SUDEP) [6]. Recently, Wandschneider et al. reported structural changes related to SUDEP in the right hippocampus and parahippocampal gyrus [7], suggesting that the autonomic disturbance underlying SUDEP might be associated with the right hemisphere. Consequently, investigating hemispheric asymmetry in postictal HRV is of utmost importance for determining the pathophysiology of SUDEP. In the present study, we aimed to characterize the influence of seizure activity of each hemisphere on HRV, as well as the power of HRV parameters to determine hemispheric laterality of seizures.

\section{Methods}

\subsection{Patients and inclusion criteria}

A total of 126 patients with focal epilepsy with unilateral focus were retrospectively assessed. These patients were consecutively admitted to 
our long-term video electroencephalogram (EEG) monitoring unit at the Department of Neurology, Kyushu University Hospital (Fukuoka, Japan) between December 1, 2011 and March 31, 2016. Inclusion criteria for patient selection were as follows: (1) clinical diagnosis of focal epilepsy; (2) availability of simultaneously recorded surface EEG, electrocardiogram (ECG), and video footage for at least one seizure; (3) at least one instance of abnormal neuroimaging data (i.e., magnetic resonance imaging [MRI], ${ }^{123}$ I-iomazenil single photon emission computed tomography, ${ }^{18} \mathrm{~F}$-fluorodeoxyglucose positron emission tomography, or magnetoencephalography) ipsilateral to ictal EEG onset; (4) no history of active cardiovascular disease; and (5) not taking cardiovascular medication. Two electroencephalographers (M.S. and T.U.) independently reviewed the ictal EEG recordings and selected focal seizures showing clearly lateralized discharges without secondary generalization or movements that obscured ictal EEG discharges. Most seizures occur during wakefulness or nonrapid eye movement (REM) sleep, and REM sleep has unique HRV patterns [8]. Thus, seizures that occurred during REM sleep were excluded to reduce confounding factors. For each patient, if more than three seizures were obtained, the first three were analyzed.

\subsection{EEG and ECG recordings}

Surface EEG electrodes were positioned according to the International 10-20 system. Simultaneous ECG was recorded via an electrode located over the left side of the anterior chest wall. Data were acquired using the Nihon Kohden video-EEG system (Nihon Kohden, Tokyo, Japan). The sampling rate was $500 \mathrm{~Hz}$.

\subsection{EEG and ECG analysis}

Electroencephalogram seizure onset and termination were visually marked by electroencephalographers (M.S. and T.U.) based on patterns that were clearly distinguishable from background activity, including rhythmic activity of variable frequency, rhythmic spiking, low amplitude fast activity, and generalized background suppression. During video analyses, the first visible clinical signs were marked as clinical seizure onset. Hence, "seizure onset" was defined as the first of either EEG seizure onset or clinical seizure onset.

The time series for ECG R-R intervals were extracted using MemCalc/ Chiram3 software (Suma-Trust, Tokyo, Japan). All R-R interval series were visually inspected in conjunction with the original ECG trace for removal of erroneously detected $R$ waves and insertion of missed $R$ beats. The time of seizure onset was set as 0 , and the baseline was calculated as the mean HR from -120 to $-60 \mathrm{~s}$. An established method was used to detect onset time of increased HR, as follows [9]: Median HR in a time window (20-s length) was compared with median HR in an adjacent time window (5-s length) to determine whether the two medians differed by $>5 / \mathrm{min}$. The onset time of a decreased HR was defined as the point at which HR decreased by $>10 \%$ of the baseline. All video recordings were carefully reviewed to check for body motion artifacts. The magnitude of HR changes was defined as the difference between the maximum and minimum HR during the periictal period.

Heart rate variability analysis was performed using the R Heart Rate Variability package written in the R language (http://rhrv.r-forge.rproject.org/). The following parameters were calculated for the 2-min period before seizure onset (preictal period) and the 2-min period after EEG seizure termination (postictal period). Additionally, selected HRV parameters for the ictal period (i.e., from seizure onset to EEG seizure termination) were calculated if the seizure was longer than $30 \mathrm{~s}$ (see Section 3.2 for details).

For the time domain analysis, standard deviations (SD) of R-R intervals (SDNN) and root mean square of successive differences (RMSSD) were calculated. For the frequency domain analysis, spectral measures were obtained using the fast Fourier transform (FFT) method. Power in the HR spectrum was divided into low frequency (LF: 0.04-0.15 Hz) and high frequency (HF: $0.15-0.4 \mathrm{~Hz}$ ) components. In the nonlinear analysis, SD1 was calculated as the SD along the minor axis, and SD2 was calculated as the SD along the major axis of an ellipse fitted to the Poincaré plot, in which each R-R interval was plotted against the previous interval.

\subsection{Statistical analysis}

JMP pro 13 software (SAS Institute, Cary, NC, USA) was used for statistical analyses. Except for onset time of HR change, ECG parameters were log transformed to approximate normality. Heart rate variability parameters were analyzed using linear mixed models for repeated measures. Seizure laterality (right vs. left hemisphere), period (pre- vs. postictal), and seizure laterality by period interaction were included as fixed effects, with seizure and subject as random effects. Seizures within the same patient are correlated with each other. Thus, we included subject as a random effect to take account of this correlation. Possible confounders (age, gender, sleep/wakefulness, temporal/extratemporal lobe epilepsy, and seizure duration) were adjusted as fixed effects. The significance of each fixed effect was tested using $F$ tests with the Kenward-Roger approximation for degrees of freedom. Simple effects were tested when the interaction was significant. In the subgroup analysis of seizures lasting more than $30 \mathrm{~s}$, HRV parameters during the ictal period were also included in the linear mixed models (see Section 3.2 for details). Two ictal HR parameters (onset time and magnitude of HR changes) were analyzed using linear mixed models. Fixed effects were seizure laterality and the possible confounders listed above, and the random effect was subject. The area under the receiver operating characteristic (ROC) curve (AUC) was calculated to determine the ability of each ECG parameter showing a significant effect of seizure laterality to lateralize seizures. To take account of the correlation within each subject, the AUCs were computed and compared among parameters using the method described by Obuchowski [10].

\subsection{Ethics committee approval}

This study was approved by the Kyushu University Institutional Review Board for Clinical Research.

\section{Results}

\subsection{Characteristics of patients and seizures}

Of the 126 patients, 30 (23.3\%) fulfilled all inclusion criteria for the present study. Among them, 25 (19.8\%) had clearly lateralized focal seizures without movements that obscured ictal EEG discharges (14 males and 11 females; mean age \pm SD, $36.2 \pm 15.0$ years; range: $16-73$ years). Epileptogenic foci were located in the left temporal lobe in 12 patients, the left frontal lobe in 1 , the right temporal lobe in 10 , the right frontal lobe in 1 , and the right hemisphere in 1 . We found no statistically significant differences in age, gender, or disease duration between patients with right vs. left epileptogenic foci. All eligible patients were righthanded. Patient characteristics are summarized in Supplementary Table 1. A total of 54 seizures were analyzed, including 27 right-sided seizures from 12 patients and 27 left-sided seizures from 13 patients. The number of seizures analyzed per patient ranged from 1 to 3 (average 2.16). Five of the 54 seizures were excluded from the onset time of HR changes analysis because no significant HR changes were observed. The remaining 49 seizures ( 26 right-sided seizures from 12 patients and 23 left-sided seizures from 13 patients) showed an ictal HR increase.

\subsection{Effect of seizure laterality on periictal HRV and HR parameters}

Fig. 1 shows representative cases of periictal HR changes associated with right- and left-sided seizures. The average power spectral density 


\section{A}

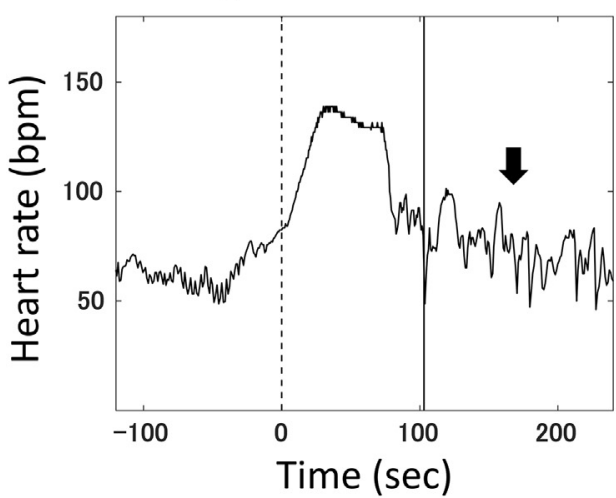

B

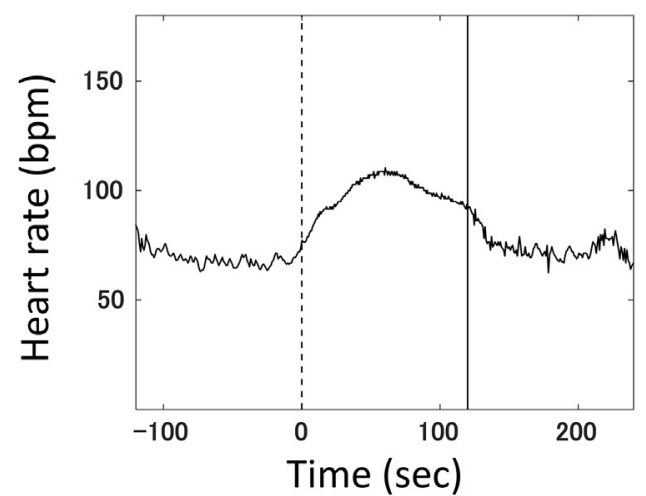

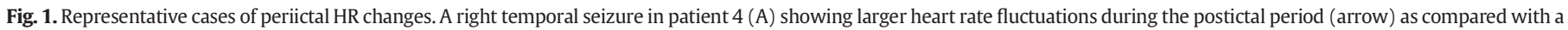
left temporal seizure in patient 23 (B). Dotted and solid lines represent electroencephalogram seizure onset and termination, respectively.

(PSD) of HRV clearly showed a tendency for greater HRV in right-sided seizures during the postictal period (Fig. 2). Table 1 summarizes the mean values for the pre- and postictal HRV parameters and ictal HR parameters. The linear mixed model analysis revealed significant interactions between seizure laterality and period for SDNN, RMSSD, LF, HF, SD1, and SD2 $(\mathrm{P}=0.0090, \mathrm{P}=0.0176, \mathrm{P}=0.0496, \mathrm{P}=0.0001, \mathrm{P}=$ 0.0436 , and $\mathrm{P}=0.044$, respectively) (Table 2 ). Subsequent simple effects tests demonstrated that SDNN, RMSSD, LF, HF, SD1, and SD2 were higher $(\mathrm{P}=0.0007, \mathrm{P}=0.0200, \mathrm{P}=0.0145, \mathrm{P}=0.0005, \mathrm{P}=$ 0.0124 , and $\mathrm{P}=0.0044$, respectively) in right-sided seizures during the postictal period (Fig. 3, Supplementary Table 3). Simple effects tests also revealed that SD2 was higher during the post- vs. preictal period in both the right- $(\mathrm{P}<0.0001)$ and left-sided $(\mathrm{P}<0.00001)$ seizures (Fig. 3, Supplementary Table 3); that RMSSD and HF were lower during
A

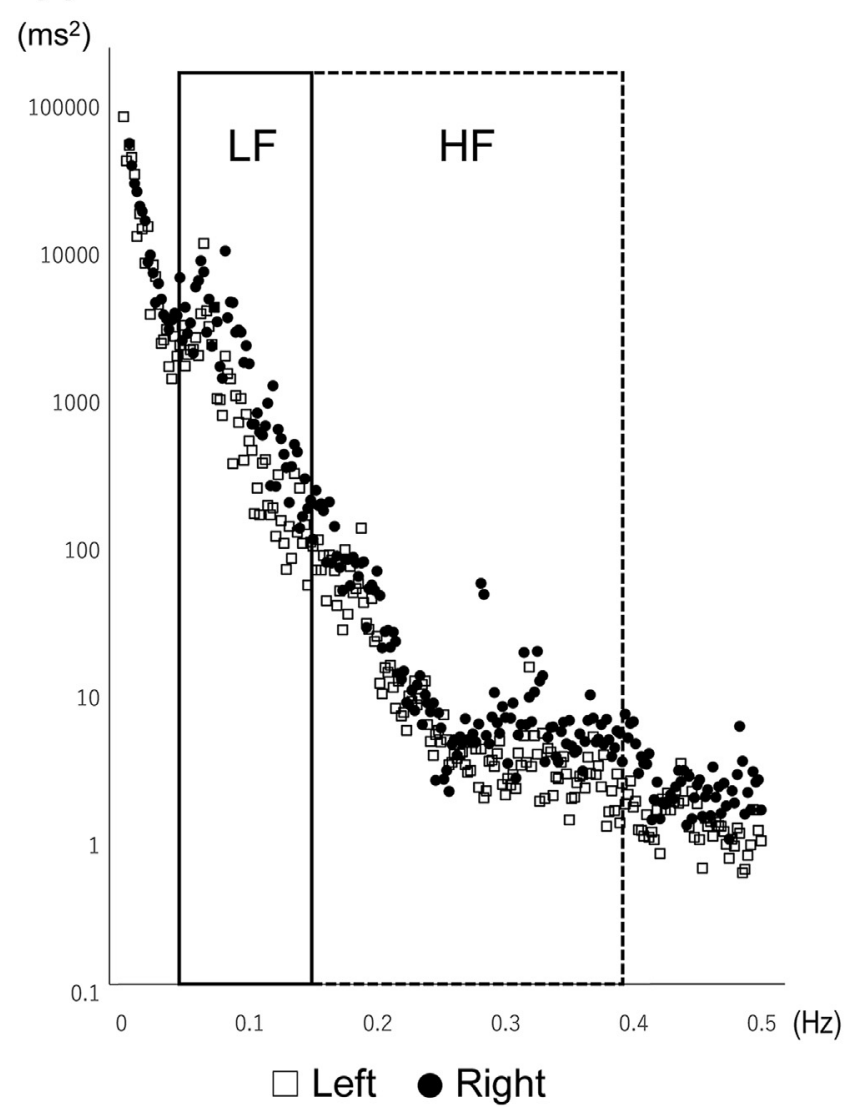

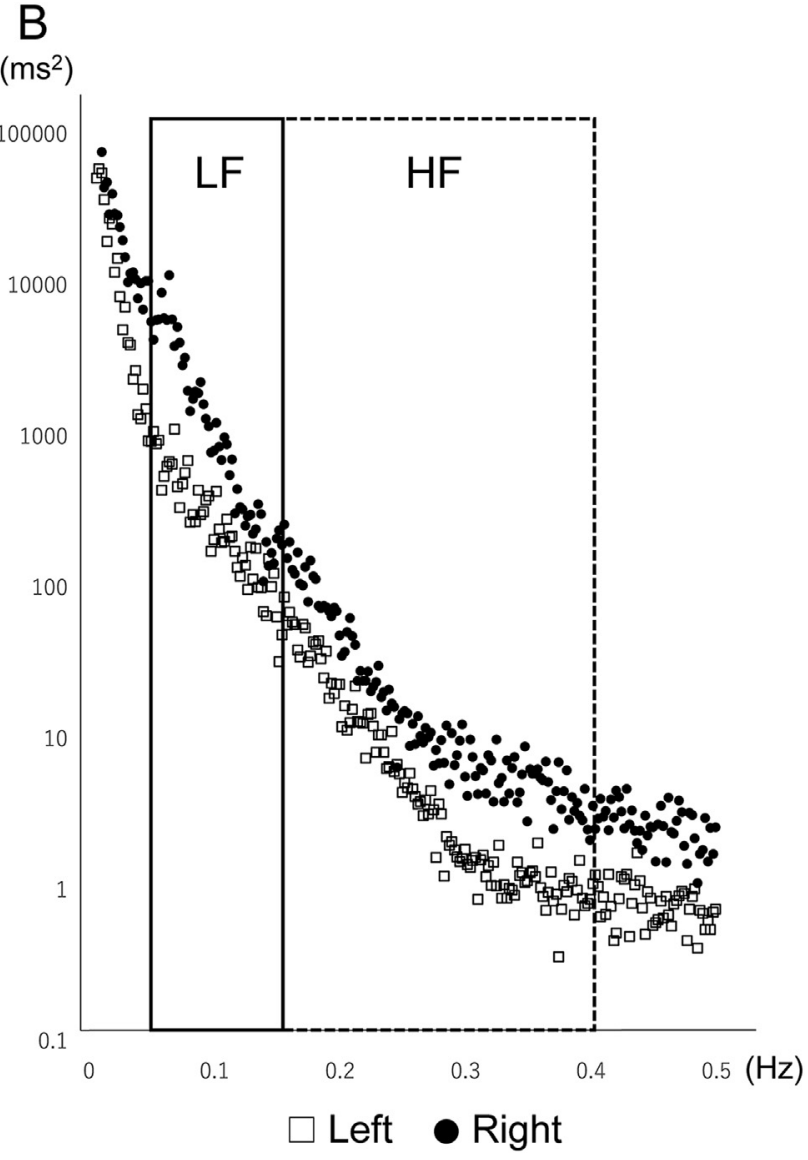

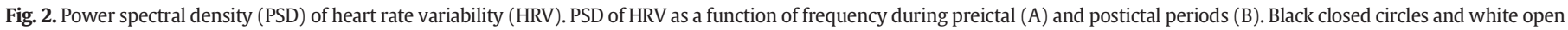

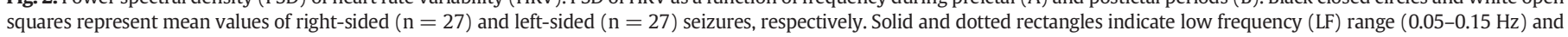
high frequency (HF) range $(0.15-0.4 \mathrm{~Hz})$, respectively. 
Table 1

Pre- and postictal heart rate variability and ictal heart rate parameters.

\begin{tabular}{|c|c|c|c|}
\hline & $\begin{array}{l}\text { All seizures } \\
(\mathrm{n}=54)\end{array}$ & $\begin{array}{l}\text { Right-sided seizures } \\
(\mathrm{n}=27)\end{array}$ & $\begin{array}{l}\text { Left-sided seizures } \\
(\mathrm{n}=27)\end{array}$ \\
\hline \multicolumn{4}{|l|}{ Preictal HRV parameters } \\
\hline SDNN (ms) & $60.85(4.31)$ & $70.93(6.60)$ & $50.77(4.92)$ \\
\hline RMSSD (ms) & $39.77(3.75)$ & $49.95(5.77)$ & $33.59(4.58)$ \\
\hline $\mathrm{LF}\left(\mathrm{ms}^{2}\right)$ & $246.81(32.24)$ & $262.11(44.63)$ & $231.51(47.14)$ \\
\hline $\mathrm{HF}\left(\mathrm{ms}^{2}\right)$ & $267.57(44.78)$ & $325.23(71.81)$ & $209.90(52.57)$ \\
\hline $\mathrm{LF} / \mathrm{HF}$ & $1.75(0.18)$ & $1.56(0.27)$ & $1.94(0.26)$ \\
\hline $\mathrm{SD} 1$ (ms) & $1.97(0.135)$ & $2.12(0.16)$ & $1.82(0.21)$ \\
\hline $\mathrm{SD} 2$ (ms) & $6.57(0.50)$ & $7.52(0.80)$ & $5.62(0.56)$ \\
\hline $\mathrm{SD} 2 / \mathrm{SD} 1$ & $3.62(0.23)$ & $3.79(0.40)$ & $3.245(0.25)$ \\
\hline \multicolumn{4}{|l|}{ Postictal HRV parameters } \\
\hline SDNN (ms) & $84.35(5.94)$ & $109.27(7.75)$ & $59.42(6.02)$ \\
\hline RMSSD (ms) & $34.29(3.17)$ & $44.50(4.68)$ & $24.08(3.33)$ \\
\hline $\operatorname{LF}\left(\mathrm{ms}^{2}\right)$ & $571.11(87.47)$ & $764.99(147.34)$ & $377.23(81.18)$ \\
\hline $\mathrm{HF}\left(\mathrm{ms}^{2}\right)$ & $269.92(70.93)$ & $425.92(122.61)$ & $113.92(60.07)$ \\
\hline $\mathrm{LF} / \mathrm{HF}$ & $5.06(0.63)$ & $2.91(0.40)$ & $7.20(1.06)$ \\
\hline $\mathrm{SD} 1$ (ms) & $2.09(0.12)$ & $2.56(0.19)$ & $1.62(0.11)$ \\
\hline $\mathrm{SD} 2(\mathrm{~ms})$ & $12.09(0.97)$ & $15.48(1.57)$ & $8.69(0.69)$ \\
\hline $\mathrm{SD} 2 / \mathrm{SD} 1$ & $5.87(0.30)$ & $6.19(0.51)$ & $5.56(0.33)$ \\
\hline \multicolumn{4}{|l|}{ Ictal HR parameters } \\
\hline Magnitude of increased ictal HR (bpm) & $43.20(2.90)$ & $53.58(4.24)$ & $42.81(3.75)$ \\
\hline Onset time of increased ictal HR (s) & $0.73(2.06)$ & $-4.34(2.39)$ & $6.47(3.10)$ \\
\hline
\end{tabular}

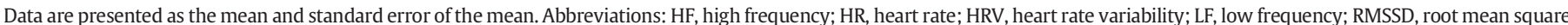
of successive differences; SD, standard deviation; SDNN, standard deviation of R-R intervals.

the post- vs. preictal period ( $\mathrm{P}=0.0011$ and $\mathrm{P}<0.0001$, respectively) in left- but not right-sided seizures (Fig. 3, Supplementary Table 3); and that SDNN, LF, and SD1 were higher during the post- vs. preictal period ( $\mathrm{P}<0.0001, \mathrm{P}<0.0001$, and $\mathrm{P}=0.0132$, respectively) in right- but not left-sided seizures (Fig. 3, Supplementary Table 3). The magnitude of increased ictal HR was larger $(P=0.0298)$, and onset time of increased ictal HR was earlier $(P=0.0146)$ in right-sided seizures (Table 2$)$. The effects of possible confounders are shown in Supplementary Table 2.

Seizure durations varied from $10 \mathrm{~s}$ to $192 \mathrm{~s}$ (median: $63 \mathrm{~s}$ ). Because HRV parameter values depend on data duration and those obtained from shorter data are less reliable [11-14], ictal period data in the present study were suboptimal for analysis using HRV parameters. However, recent studies have shown that RMSSD and HF are less sensitive to data duration [12] and can be reliably calculated from data that are approximately $30 \mathrm{~s}$ in duration $[13,14]$. Therefore, we performed ictal HRV analysis of RMSSD and HF for seizures lasting more than $30 \mathrm{~s}$ (48 [88.8\%] seizures, including 24 right-sided seizures from 12 patients and 24 left-sided seizures from 13 patients). When preictal, ictal, and postictal data were included in the linear mixed model analysis, interactions between seizure laterality and period were significant for RMSSD and $\mathrm{HF}$ ( $\mathrm{P}=0.0288$ and $\mathrm{P}<0.0001$, respectively). Simple effects tests revealed that $\mathrm{HF}$ were higher in right- than left-sided seizures during the ictal and the postictal periods $(\mathrm{P}=0.0306$ and $\mathrm{P}=0.0034$, respectively; Fig. 4). Simple effects of period were significant for RMSSD and HF in both right-sided seizures $(\mathrm{P}=0.0093$ and $\mathrm{P}=0.0024$, respectively) and left-sided seizures ( $\mathrm{P}<0.0001$ and $\mathrm{P}<0.0001$, respectively). Subsequent multiple comparison tests with Bonferroni correction revealed that RMSSD and HF were lower during the ictal vs. preictal period in both right-sided $(\mathrm{P}=0.0321$ and $\mathrm{P}=0.0162$, respectively) and left-sided ( $\mathrm{P}=0.0006$ and $\mathrm{P}<0.0001$, respectively) seizures, higher during the post- vs. ictal period in right-sided seizures $(\mathrm{P}=0.036$ and $\mathrm{P}$ $=0.0027$, respectively), and lower during the post- vs. preictal period in left-sided seizures ( $\mathrm{P}=0.0003$ and $\mathrm{P}<0.0001$, respectively) (Fig. 4).

Patients were in the supine position for 35 seizures (64.8\%), were sitting in 11 seizures (20.3\%), and changed body position in 8 seizures (14.8\%). To assess the possible effects of body position on the main results, seizures in the supine position (18 right-sided seizures form 9 patients and 17 left-sided seizures from 9 patients) were separately analyzed from other seizures. In doing so, the results were consistent with those of the main analysis. Namely, there were significant interactions

Table 2

Results of linear mixed model analysis.

\begin{tabular}{|c|c|c|c|c|c|c|}
\hline \multirow[t]{2}{*}{ Variables } & \multicolumn{2}{|c|}{$\begin{array}{l}\text { Seizure laterality (right vs. left } \\
\text { hemisphere) }\end{array}$} & \multicolumn{2}{|c|}{ Period (pre- vs. postictal) } & \multicolumn{2}{|c|}{$\begin{array}{l}\text { Interaction (seizure laterality } \times \\
\text { period) }\end{array}$} \\
\hline & F value (df) & P value & F value (df) & P value & F value (df) & P value \\
\hline SDNN & $9.83(1,16.5)$ & 0.0062 & $25.97(1,52.0)$ & $<0.0001$ & $7.36(1,52.0)$ & 0.0090 \\
\hline RMSSD & \multicolumn{2}{|l|}{ 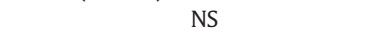 } & $5.99(1,52.0)$ & 0.0177 & $6.01(1,52.0)$ & 0.0176 \\
\hline $\mathrm{LF}$ & \multicolumn{2}{|c|}{ NS } & $21.69(1,52.0)$ & $<0.0001$ & $4.04(1,52.0)$ & 0.0496 \\
\hline $\mathrm{HF}$ & $7.99(1,17.6)$ & 0.0113 & $7.69(1,52.0)$ & 0.0077 & $17.30(1,52.0)$ & 0.0001 \\
\hline $\mathrm{LF} / \mathrm{HF}$ & \multicolumn{2}{|c|}{ NS } & $40.00(1,52.0)$ & $<0.0001$ & \multicolumn{2}{|c|}{ NS } \\
\hline SD1 & \multicolumn{2}{|c|}{ NS } & \multicolumn{2}{|c|}{ NS } & $4.27(1,52.0)$ & 0.0436 \\
\hline SD2 & $6.27(1,17.4)$ & 0.0225 & $85.23(1,52.0)$ & $<0.0001$ & $4.26(1,52.0)$ & 0.044 \\
\hline $\mathrm{SD} 2 / \mathrm{SD} 1$ & \multicolumn{2}{|c|}{ NS } & $59.07(1,52.0)$ & $<0.0001$ & \multicolumn{2}{|c|}{ NS } \\
\hline Magnitude of increased ictal HR & $5.60(1,17.4)$ & 0.0298 & \multicolumn{2}{|c|}{$\mathrm{NI}$} & \multicolumn{2}{|c|}{$\mathrm{NI}$} \\
\hline Onset time of increased ictal HR & $8.48(1,10.6)$ & 0.0146 & \multicolumn{2}{|c|}{$\mathrm{NI}$} & \multicolumn{2}{|c|}{$\mathrm{NI}$} \\
\hline
\end{tabular}

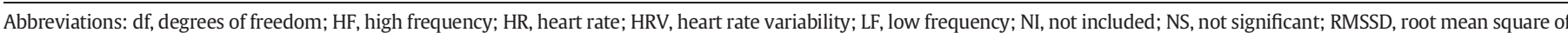
successive differences; SD, standard deviation; SDNN, standard deviation of R-R intervals. 
between seizure laterality and period for SDNN, RMSSD, and HF ( $\mathrm{P}=$ $0.0268, \mathrm{P}=0.0177$, and $\mathrm{P}=0.0015$, respectively) (Supplementary Table 4); higher postictal SDNN $(\mathrm{P}=0.0159)$ and $\mathrm{HF}(\mathrm{P}=0.0234)$ in right-sided seizures; lower post- vs. preictal RMSSD $(P=0.0012)$ and HF $(P=0.0003)$ in left-sided seizures; and higher post- vs. preictal SDNN in right-sided seizures $(\mathrm{P}<0.0001)$ (Supplementary Table 5).

\subsection{ROC analysis}

Table 3 shows the AUCs for postictal SDNN, RMSSD, LF, HF, SD1, SD2, and magnitude and onset time of increased HR. Postictal HF showed the greatest AUC (0.87). There were no significant differences in these AUCs.

\section{Discussion}

The main new findings of our study were as follows: (1) overall, short-term, and long-term HRV were significantly higher in right- vs. left-sided seizures during the postictal period; (2) after seizures, short-term HRV was decreased in left- but not right-sided seizures; and (3) postictal HRV parameters, especially HF, can discriminate right- and left-sided seizures with a high accuracy. To our knowledge,

\section{B}

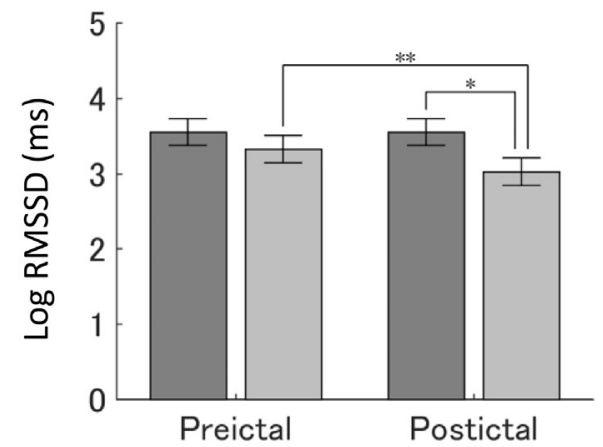

D

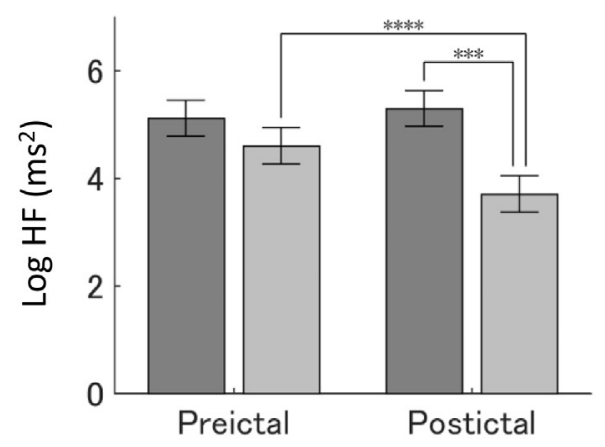

F

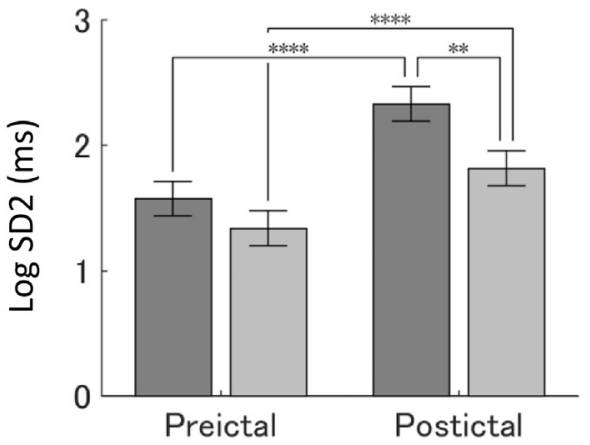

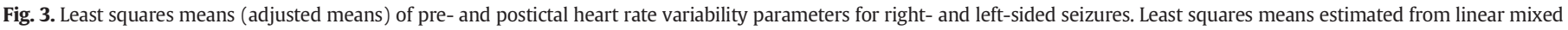

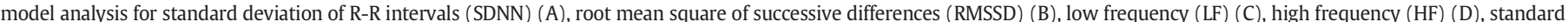

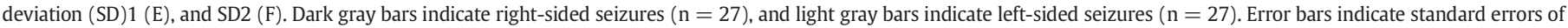

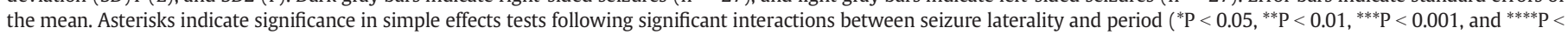
0.0001). 
A

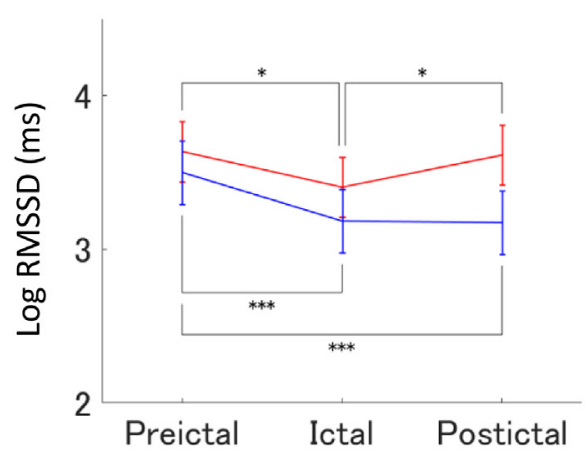

— Right-sided seizure
B

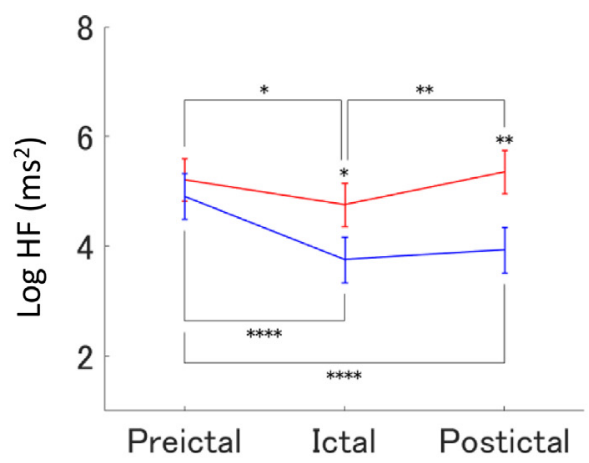

Left-sided seizure

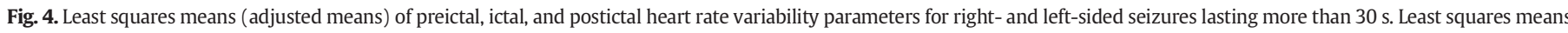

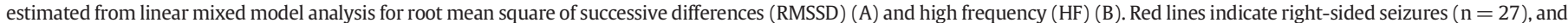

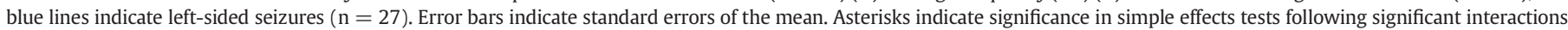

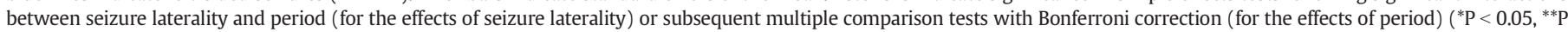
$<0.01,{ }^{* * *} \mathrm{P}<0.001$, and ${ }^{* * * *} \mathrm{P}<0.0001$ ). (For interpretation of the references to color in this figure legend, the reader is referred to the web version of this article.)

this is the first study to detail robust effects for seizure laterality on postictal HRV.

We found higher postictal SDNN, RMSSD, LF, HF, SD1, and SD2 in right-sided seizures. Although SDNN, LF, and SD2 reflect sympathetic and parasympathetic activity, RMSSD, HF, and SD1 are known to be pure measures of parasympathetic activity $[4,11,15]$. Therefore, our results indicate that there is higher postictal parasympathetic activity in right-sided seizures. Parameters of sympathovagal balance (LF/HF and SD2/SD1) were increased after seizures and had no interactions with seizure laterality, and parasympathetic parameters (RMSSD and HF) were decreased after left-sided seizures. These findings are consistent with known ictal sympathetic activation with parasympathetic suppression [16,17]. However, postictal parasympathetic parameters were similar to (RMSSD and HF) or higher than (SD1) those during the preictal period in right-sided seizures. Additionally, our subgroup analysis of seizures lasting more than $30 \mathrm{~s}$ revealed that although ictal parasympathetic parameters (RMSSD and HF) were lower than those during preictal period in both right- and left-sided seizures, they were lower than those during postictal period in right- but not left-sided seizures. These results suggest that parasympathetic suppression recovers while sympathetic activity remains significant during the postictal period in right-sided seizures. Such postictal sympatho-parasympathetic coactivation can produce autonomic instability [6]. Although the contribution of each hemisphere to SUDEP is unknown, eight out of 11 monitored SUDEP cases in a systematic survey showed right-sided focus [18], and an MRI study reported increased right hippocampal and

Table 3

Results of the receiver operating characteristic curve analysis for discriminating rightand left-sided seizures.

\begin{tabular}{ll}
\hline Parameters & AUC $(95 \% \mathrm{CI})$ \\
\hline Postictal SDNN & $0.83(072-0.94)$ \\
Postictal RMSSD & $0.81(0.68-0.94)$ \\
Postictal LF & $0.73(0.57-0.89)$ \\
Postictal HF & $0.87(0.77-0.98)$ \\
Postictal SD1 & $0.79(0.65-0.94)$ \\
Postictal SD2 & $0.79(0.64-0.94)$ \\
Magnitude of increased ictal HR & $0.67(0.47-0.87)$ \\
Onset time of increased ictal HR & $0.71(0.53-0.88)$ \\
\hline
\end{tabular}

Abbreviations: AUC, area under the receiver operating characteristic curve; $\mathrm{CI}$, confidence interval; HF, high frequency; HR, heart rate; LF, low frequency; SD, standard deviation; SDNN, standard deviation of R-R intervals; RMSSD, root mean square of successive differences. parahippocampal gyrus volume in patients with SUDEP [7]. Thus, our findings suggest that involvement of the right hemisphere may be associated with autonomic instability underlying SUDEP.

To the best of our knowledge, only three studies have analyzed the effects of seizure laterality on postictal HRV $[17,19,20]$. Unlike our study, these studies focused on temporal lobe epilepsy (TLE). Our subgroup analysis of patients with TLE revealed comparable results to the main analysis (Supplementary Tables 6, 7). Our results are partially consistent with the findings of Adjei et al. who examined subclinical seizure patterns and found that patients with left TLE had lower overall HRV (SDNN) compared with patients with right TLE [19]. However, they did not analyze other HRV parameters. Szurhaj et al. analyzed shortterm HRV (HF variability index) in individuals with TLE, but found no effect of seizure laterality [17]. The difference between their findings and ours may be due to the parameters chosen; indeed, we found that not all parasympathetic parameters were affected by seizure laterality. Romigi et al. reported that postictal SDNN, RMSSD, LF, HF, and LF/HF were not influenced by laterality of seizure activity in patients with TLE [20]. There are notable differences in patient characteristics between their study and ours: they analyzed newly diagnosed patients, whereas most of our patients were drug-resistant and had long disease durations. Disease severity or chronic effects of repeated epileptic discharge might reinforce differences between right- and left-sided seizures in postictal HRV.

In accordance with previous studies [21,22], right-sided seizures showed larger ictal HR increase, suggesting higher sympathetic and/or lower parasympathetic activity [23]. In contrast, our results on HRV indicate higher postictal parasympathetic activity in right-sided seizures. Koizumi et al. reported that hypothalamic stimulation induced sympathetic activation and diminished the baroreflex, and that the baroreflex reappeared and induced parasympathetic activation after stimulation was stopped [24]. Hence, our results may indicate that a greater HR increase in right-sided seizures is accompanied by higher blood pressure, which triggers larger baroreflex-mediated parasympathetic activation after termination of seizures. However, our subgroup analysis of seizures lasting more than $30 \mathrm{~s}$ revealed that HF was higher in rightsided seizures during not only the postictal but also the ictal period. Thus, greater ictal parasympathetic suppression in left-sided seizures may also contribute to the difference in postictal parasympathetic activity between right- and left-sided seizures.

Subgroup analysis of seizures in the supine position revealed comparable results to the main analysis in SDNN, RMSSD, and HF. Thus, 
differences in these parameters between right- and left-sided seizures were not caused by differences in body position. Although we did not include seizures presenting with movements that obscure ictal EEG discharges, mild motor symptoms such as limb automatism were observed in 43 (79.6\%) seizures. However, we consider that the effects of motor symptoms on our results were limited, and for the following reasons: (1) movements usually increase HR and decrease parasympathetic HRV parameters, whereas both of these parameters were higher during right-sided seizures; and (2) differences in HRV parameters between right- and left-sided seizures were more significant after motor symptoms (postictal period) than during them (ictal period).

It is worth noting that HRV parameters display high interindividual variability. Thus, although we found that various postictal HRV parameters were significantly higher in right-sided seizures at the group level, it could be difficult to define cutoff values to distinguish right- from leftsided seizures in individual patients. Modification of HRV parameters such as normalization with baseline values might be useful to translate our results into clinical practice in the future.

Our study has several limitations. First, we did not consider other factors that potentially affect the HR and HRV, such as antiepileptic drugs (AEDs). However, AEDs likely have a minimal influence on our results because they were discontinued or tapered during long-term video-EEG in 49 seizures (90.7\%). Additionally, we obtained similar results when we only analyzed these 49 seizures (Supplementary Tables 8 , 9 ). Second, the number of seizures per patient varied from 1 to 3 . Therefore, patients with 3 seizures may have introduced a bias. However, this bias was minimalized by using linear mixed models. Third, it may be difficult to directly compare our results with other studies because there is no standard methodology for analyzing seizure-induced HR and HRV changes [25]. Indeed, further work is needed to establish a unified approach in this field of research. Fourth, although many seizures propagate to the contralateral hemisphere in the early phase, we did not test whether our findings can be generalized to such seizures. Because SUDEP is associated with seizures involving both hemispheres [6], this should be explored in the future to clarify the contribution of the right hemisphere to SUDEP. Fifth, effects of the location of epileptic foci were not tested in detail. Although the subgroup of patients with TLE showed results that were similar to the whole group, the number of patients with extra-TLE was too small for separate analysis. Larger studies are needed to test whether the observed effects of seizure laterality on postictal HRV parameters are specific to TLE or not. Sixth, because of the retrospective nature of this study, video footage of the interictal period was not always available. Thus, we could not obtain HRV parameters of the basal period, which can be different from those of the preictal period [20]. Further prospective studies are essential to explore the possible effects of seizure laterality on the transition from the basal to the preictal period in the autonomic nervous system.

\section{Acknowledgments}

We would like to thank E. Watanabe (Division of Clinical Chemistry and Laboratory Medicine, Kyushu University Hospital) for her cooperation. We thank Nia Cason, Ph.D., and Rachel James, Ph.D., from Edanz Group (www.edanzediting.com/ac) for editing a draft of this manuscript.

\section{Funding}

This work was supported by the Grants-in-Aid for Scientists (Nos. 15K09340, 15K19491, 16K09722, 26461273, and 26461312) from the Ministry of Education, Culture, Sports, Science and Technology in Japan.

\section{Declaration of competing interest}

R.Y. serves as a managing editor of Clinical and Experimental Neuroimmunology. He has received speaking fees from Nihon
Pharmaceutical. J.K. serves as a member of the editorial boards of Multiple Sclerosis Journal, Multiple Sclerosis and Related Disorders, BMC Medicine, PLoS One, Expert Review of Neurotherapeutics, Intractable and Rare Diseases Research, Neurology and Clinical Neuroscience, Acta Neuropathologica Communications, Bio Med Research International, Journal of Neurology and Psychology, Scientific World Journal, Journal of the Neurological Sciences, Neurology, Psychiatry and Brain Research, Annals of Neurology \& Neurosciences, and Neuroimmunology \& Neuroinflammation. He has received honoraria from Bayer Healthcare, Biogen Idec, Novartis Pharma, Eisai, Mitsubishi Tanabe Pharma, Sanofi, and Chugai. The remaining authors have no conflicts of interest.

\section{Appendix A. Supplementary data}

Supplementary data to this article can be found online at https://doi. org/10.1016/j.yebeh.2019.05.026.

\section{References}

[1] Wittling W, Block A, Genzel S, Schweiger E. Hemisphere asymmetry in parasympathetic control of the heart. Neuropsychologia 1998;36:461-8. https://doi.org/10. 1016/S0028-3932(97)00129-2.

[2] Oppenheimer S, Gelb A, Girvin JP, Hachinski VC. Cardiovascular effects of human insular cortex stimulation. Neurology 1992;42:1727-32. https://doi.org/10.1212/ WNL.42.9.1727.

[3] Hilz MJ, Dütsch M, Perrine K, Nelson PK, Rauhut U, Devinsky O. Hemispheric influence on autonomic modulation and baroreflex sensitivity. Ann Neurol 2001;49: 575-84. https://doi.org/10.1002/ana.1006.

[4] Valderrama M, Navarro V, Le Van Quyen M. Heart rate variability as measurement of heart-brain interactions. Epilepsies 2010;22:194-200. https://doi.org/10.7453/ gahmj.2014.073.

[5] Sevcencu C, Struijk JJ. Autonomic alterations and cardiac changes in epilepsy. Epilepsia 2010;51:725-37. https://doi.org/10.1111/j.1528-1167.2009.02479. $\mathrm{x}$

[6] Devinsky O, Hesdorffer DC, Thurman DJ, Lhatoo S, Richerson G. Sudden unexpected death in epilepsy: epidemiology, mechanisms, and prevention. Lancet Neurol 2016; 15:1075-88. https://doi.org/10.1016/S1474-4422(16)30158-2.

[7] Wandschneider B, Koepp M, Scott C, Micallef C, Balestrini S, Sisodiya SM, et al. Structural imaging biomarkers of sudden unexpected death in epilepsy. Brain 2015;138: 2907-19. https://doi.org/10.1093/brain/awv233.

[8] Chouchou F, Desseilles M. Heart rate variability: a tool to explore the sleeping brain? Front Neurosci 2014;8:402https://www.frontiersin.org/articles/10.3389/fnins.2014. 00402.

[9] van Elmpt WJ, Nijsen TME, Griep PAM, Arends JBAM. A model of heart rate changes to detect seizures in severe epilepsy. Seizure 2006;15:366-75. https://doi.org/10. 1016/i.seizure.2006.03.005.

[10] Obuchowski NA. Nonparametric analysis of clustered ROC curve data. Biometrics 1997;53:567-78. https://doi.org/10.2307/2533958.

[11] Task Force of the European Society of Cardiology and the North American Society of Pacing and Electrophysiology. Heart rate variability: standards of measurement, physiological interpretation and clinical use. Circulation 1996;93:1043-65. https:// doi.org/10.1161/01CIR.93.5.1043.

[12] McNames J, Aboy M. Reliability and accuracy of heart rate variability metrics versus ECG segment duration. Med Biol Eng Comput 2006;44:747-56. https://doi.org/10. 1007/s11517-006-0097-2.

[13] Salahuddin L, Cho J, Jeong MG, Kim D. Ultra short term analysis of heart rate variability for monitoring mental stress in mobile settings. Conf Proc IEEE Eng Med Biol Soc 2007:4656-9. https://doi.org/10.1109/IEMBS.2007.4353378.

[14] Baek HJ, Cho CH, Cho J, Woo JM. Reliability of ultra-short-term analysis as a surrogate of standard 5-min analysis of heart rate variability. Telemed J E Health 2015; 21:404-14. https://doi.org/10.1089/tmj.2014.0104.

[15] Vanderlei LCM, Pastre CM, Hoshi RA, de Carvalho TD, de Godoy MF. Basic notions of heart rate variability and its clinical applicability. Rev Bras Cir Cardiovasc 2009;24: 205-17. https://doi.org/10.1590/S0102-76382009000200018.

[16] Poh MZ, Loddenkemper T, Reinsberger C, Swenson NC, Goyal S, Madsen JR, et al. Autonomic changes with seizures correlate with postictal EEG suppression. Neurology 2012:78:1868-76. https://doi.org/10.1212/WNL.0b013e318258f7f1.

[17] Szurhaj W, Troussière AC, Logier R, Derambure P, Tyvaert L, Semah F, et al. Ictal changes in parasympathetic tone: prediction of postictal oxygen desaturation. Neurology 2015;85:1233-9. https://doi.org/10.1212/WNL.0000000000001994.

[18] Ryvlin P, Nashef L, Lhatoo SD, Bateman LM, Bird J, Bleasel A, et al. Incidence and mechanisms of cardiorespiratory arrests in epilepsy monitoring units (MORTEMUS): a retrospective study. Lancet Neurol 2013;12:966-77. https://doi. org/10.1016/S1474-4422(13)70214-X

[19] Adjei P, Surges R, Scott CA, Kallis C, Shorvon S, Walker MC. Do subclinical electrographic seizure patterns affect heart rate and its variability? Epilepsy Res 2009;87:281-5. https://doi.org/10.1016/j.eplepsyres.2009.08.011.

[20] Romigi A, Albanese M, Placidi F, Izzi F, Mercuri NB, Marchi A, et al. Heart rate variability in untreated newly diagnosed temporal lobe epilepsy: evidence for ictal sympathetic dysregulation. Epilepsia 2016;57:418-26. https://doi.org/10.1111/epi. 13309. 
[21] Chen W, Guo CL, Zhang PS, Liu C, Qiao H, Zhang JG, et al. Heart rate changes in partial seizures: analysis of influencing factors among refractory patients. BMC Neurol 2014;14(135). https://doi.org/10.1186/1471-2377-14-135.

[22] Leutmezer F, Schernthaner C, Lurger S, Potzelberger K, Baumgarner C. Electrocardiographic changes at the onset of epileptic seizures. Epilepsia 2003;44:348-54. https://doi.org/10.1046/j.1528-1157.2003.34702.x.

[23] Sevcencu C, Nielsen TN, Struijk JJ. Changes in vagus nerve activity associated with ictal tachycardia in pigs. Epilepsy Res 2016;128:52-60. https://doi.org/10.1016/j. eplepsyres.2016.10.007.
[24] Koizumi K, Kollai M. Control of reciprocal and non-reciprocal action of vagal and sympathetic efferents: study of centrally induced reactions. J Auton Nerv Syst 1981;3:483-501. https://doi.org/10.1016/0165-1838(81)90082-5.

[25] Eggleston KS, Olin BD, Fisher RS. Ictal tachycardia: the head-heart connection. Seizure 2014;23:496-505. https://doi.org/10.1016/j.seizure.2014.02.012. 